\title{
Research on New College Reading Promotion Practice based on the Popular Variety Mode
}

\author{
Junbo Dai \\ The Library \\ Tonghua Normal University \\ Tonghua, China 134002
}

\author{
Ji Qi \\ Tonghua Municipal Bureau of Human resources and Social \\ Jilin, China
}

\author{
Hongming Liu \\ Pingmei First Senior High School \\ Chifeng, China
}

\begin{abstract}
In the background of building a nationwide reading atmosphere, the reading promotion work has gradually become the focus of the work of university library. In order to stimulate the enthusiasm of readers to walk into the library and approach read, Tonghua Normal University Library has carried out a new reading promotion practice activity starting from "the most favorite thing of readers", based on popular variety mode, by combining recreational and sports activities, collected literature retrieval, quality book recommendation, the retrieval of electronic resources and other quality-oriented education. The paper expounded the design concepts, procedures and implementation methods of the case, and summarized relevant experience and shortcomings to drive the college reading promotion work and make it more efficient, more acceptable to readers, and easy to implement.
\end{abstract}

Keywords—variety; reading promotion

\section{INTRODUCTION}

"I hope we can form a nationwide reading atmosphere, and it can be everywhere." This is the answer of Premier $\mathrm{Li}$ Keqiang during the two sessions this year in response to reporters on the issue of reading. Meanwhile, "the nationwide reading" has been written in the government work reports for two consecutive years. This fully reflects that the party and the state highly value the reading promotion work. As a college librarian, we should deeply recognize the responsibility to do reading promotion well among college students. We should fully understand them and know what they love to help the pillars of the state integrate into reading atmosphere and enjoy the pleasure of reading, integrate the reading promotion work into college student communities and draw near to the heart of readers. Therefore, the library of my university has planned a reading promotion practice activity starting from "Running Man", the most favorite variety show among college student, in the hottest variety mode, and we have achieved a very good effect.

\section{The REASON Why We USE THE POPUlAR VARIETY SHOW MODE TO PROMOTE THE WORK OF READING}

First of all, the most basic task of college reading promotion work is to let readers walk into the library and approach reading. At present, in some domestic colleges and universities, especially provincial colleges and universities similar to my university, the library use effect is not ideal. The understanding of students and their use of library are an obvious contrast to the huge financial and human input of library. The level of resources utilization is very low. Therefore, it is the basic task of the reading promotion work to let readers walk into library, know resources and approach reading. The popular variety show is enthusiastically responded by readers. We have built a popular passionate image out of a traditional tedious library to stimulate the readers' curiosity and arouse them to approach library. We take it as an opportunity to carry out in-depth reading promotion work.

Secondly, the focus of reading promotion work is to put this work into the reader's heart. Reviewing previous reading promotion mode, we have invested a lot of energy to carry out the reading speech contest, film screenings, good book recommendation, book rafting and various reading promotion activities. But for a long time, the enthusiasm and voluntary participation of readers obviously decline, and some even participate just for the completion of work. It becomes two different things to participate in activities and to approach reading. The effect of activities is not ideal. It is necessary for the library to explore a new way to promote the reading of the readers, so that college students would like to participate in the reading promotion activities.

Thirdly, the enthusiasm level of reading promotion work greatly affects the effect of the work. The task-based reading promotion activities cannot attract readers' active participation. The use of the positive impact of the popular variety show can fully mobilize the reader's enthusiasm. The readers can even put forward their views and offer strategies for the library reading promotion activities according to the variety show 
content. Such active participation atmosphere greatly improved the reading promotion work effect.

Finally, college students' age characteristics, psychological characteristics and interest orientation require us to make continuous innovation in the reading promotion work. College students are full of vigor and vitality, bubble with enthusiasm, and yearn for new things and new fashion. The traditional reading promotion activities are difficult to stimulate readers' participation enthusiasm. Therefore, it is very necessary to improve and innovate the traditional reading promotion mode according to the characteristics of their age.

In 2014, the most popular variety show "Running Man" is deeply loved by college students. Our school made an investigation on 3231 readers randomly selected, and we found that all respondents have ever watched this show. $78.9 \%$ of respondents have watched all issues of the show. $92.1 \%$ of the respondents love this show very much. Therefore, our library designed a reading promotion activity of "Running Reader" according to the mode of "Running Man", taking it as a bold attempt in new reading promotion mode.

\section{THE DEVELOPMENT AND IMPLEMENTATION OF THE NEW REAding PROMOTION Mode}

\section{A. Organization and Planning}

1) Preliminary plan: Rely on various resources of library, highlight the theme of book retrieval and reading, and combine the featured rules of "Running Man". Integrate book retrieval, quality reading, arrangement of book classification, electronic database retrieval, utilization of library website, show of reading ability, journals and newspaper retrieval, WeChat search and many other information quality education contents into "Two Men and Three Feet", "Double Rope Skipping", "Book Name Matching", "Book Name Guess", "Book Telling", "Domino Palace Building", "Tearing Name Tag", "Matching Clues" and other recreational and sports activities, and sort out six game links, including "Crossing Book Mountain", "Book, Ladder of Human Progress", "Heaven, Appearance of Library", "Seeking Clues and Obtaining Literature", "Finding Library Card and Tearing Name Tag" and "Book Recommendation". We developed the activity plan with above contents. The plan has described the rules of the game, scoring criteria, winning reward, voting principles of the public judge and other details associated with the game, and detailedly introduced names of activities, background, purpose, slogans, participant selection, activity time, location and other contents.

2) The optimization of plan process: The activity is designed to fully mobilize the readers' active participation in the library reading promotion activities. We organized student representatives of all faculties to discuss the plan in order to optimize all processes in the plan. In order to fully reflect the views of student readers, readers participating in the discussion are all student council leaders and student librarians. We collected a large number of ideas and opinions related to the games in discussion. These ideas and opinions are true reflections of student's life experience, so the entire activity process is full of vitality and attraction. What's more, this discussion has closed the distance between library and readers. It was a thorough and effective communication. We began to realize that the reading promotion work couldn't only be limited to the mode of "library holding activity and readers participating in". "Library and readers should jointly make reading full of pleasure". Only by getting readers' recognition, can the resources of the library play its due role. The reading promotion work should start from what readers need and love, rather than saying to itself or being mysterious and arrogant.

3) Staff deployment stage: As a supplementary teaching department, the staff composition of library is slightly weak. Take my library as an example. We have a total of 40 staff in library, including 19 temporary staff. The 40 staff shall manage millions of books, be responsible for the normal operation of library and the reading promotion work among 14000 readers. Even if there is no such large-scale reading promotion activity, the workload is quite large. This development of this activity is a great challenge. In order to enable the smooth development of this activity, my library carried out a detailed deployment of staff. We divided our staff into program planning group, publicity group, the props group, the medical group, the security group, the camera shooting group and the referee group. We arranged designated personnel to take charge of poster design and making, props arrangement in each game link, in-depth publicity in each faculty, and every other detail, so that the development of the whole activity had a strong driving power.

4) Publicity stage: The breadth of reading promotion depends on the propaganda to a large extent. A strong propaganda process is very necessary to achieve a good effect in developing activities and get readers' recognition. First, the chief librarian, on behalf of library, applies to the leaders of party and administrations for the organization and implementation of this activity. The activity plan is complete, concrete, fresh and substantial, and has a clear guiding effect, so it quickly get passed and obtained the support of the university leaders. For this purpose, the school had convened a "Scholarly Campus" reading promotion activity organization and planning meeting among the leaders of the party and administrations of each faculty. This activity has gained the full cooperation of all faculties. The activity posters were posted in campus. We also posted electric posters in campus notice system, campus website, library website, library WeChat platform, readers service group, administrator service group and etc.. Due to leadership support, complete plan and fully prepared materials, we got a good effect in publicity phase. We received 107 telephone consultations, 374 consultations through library WeChat, 34 consultations through QQ, and 87 visits on the notice of "Running Readers" through library website. The sixth link of the game is book recommendation. The 100 recommended books rapidly run short in library. The circulation increased significantly.

5) Member selection and participation stage: There are 15 faculties in the university. In this activity, we selected 2 students in each faculty to take part in game and arranged one cameraman. Readers took part in the activity actively, and we have got a good achievement. In order to win honors for each faculty, many faculties carried out their own reading promotion activities. For example, the Foreign Language 
Faculty organized the Chinese and foreign classics' plot scene performance; the Faculty of Physics and the Faculty of Computer organized the reading speech contest; the Faculty of Arts and the Faculty of Music organized the quality book list reading contest; the Historical and Geography Faculty and the Faculty of Political Science and Law organized the master reading lecture. These reading promotion activities have driven the reading enthusiasm of readers, and also selected members who love reading, are diligent in reading and good at reading for the activity of "Running Reader". It has laid a foundation for this activity, and showed the departments of the university attached great importance to this activity.

6) The props and scene preparation stage: There are three rounds in this game and six game links in each round. Every link is different from each other, so it needs to prepare a lot of props and scenes. It totally involved 1032 articles. The members of props group should organize young staff for "foretaste" before the game according to rules of the game, and sum up experience in order to make the props work plan. The use of each prop and the arrangement of each scene should be designated to personnel. In addition, the props group could also improve and enrich props and make it more secure and easier to implement.

\section{B. Activity Implementation}

After careful preparation, the game was scheduled for April 22nd. The game was divided into three rounds. The mode was different in each round. Each round produced a champion. The rules and implementation of the game were as follows.

In the game, the library combined the search numbers of 5 quality books with 5 library scene pictures. Each picture was split into four pieces. Then there were 20 puzzle clue pieces. Enveloped these pieces and stuck on the display board randomly, and drew the clue pieces on the display board according to the rank of each game link.

1) Crossing book mountain: Mode 1: there are two persons in each group. They need to cross the obstacle of books in a two-men three-leg way. The group that first arrive the end wins. If they knock down barriers in midway, they need to lift up and then re-cross the obstacle. When they arrives the end, they need to jump together and take photo and send it to WeChat. Then they can get one clue piece. The winning group can get one more clue piece.

Mode 2: there are two persons in each group. They shall take 3 continuous rope skipping and then cross an obstacle of books. The group that first arrive the end wins. If they knock down barriers in midway, they need to lift up and then re-cross the obstacle. When they arrives the end, they need to jump together and take photo and send it to WeChat. Then they can get one clue piece. The winning group can get one more clue piece.

Mode 3: there are two persons in each group. One is a commander; the other shall be covered eyes to trample balloons. The group that breaks balloons at the largest number within 20 seconds wins. After this, they need to jump together and take photo and send it to WeChat. Then they can get one clue piece. The group that upset the obstacle or with the eyes uncovered shall stop trample balloons. The winning group can get one more clue piece. "Fig. 1"

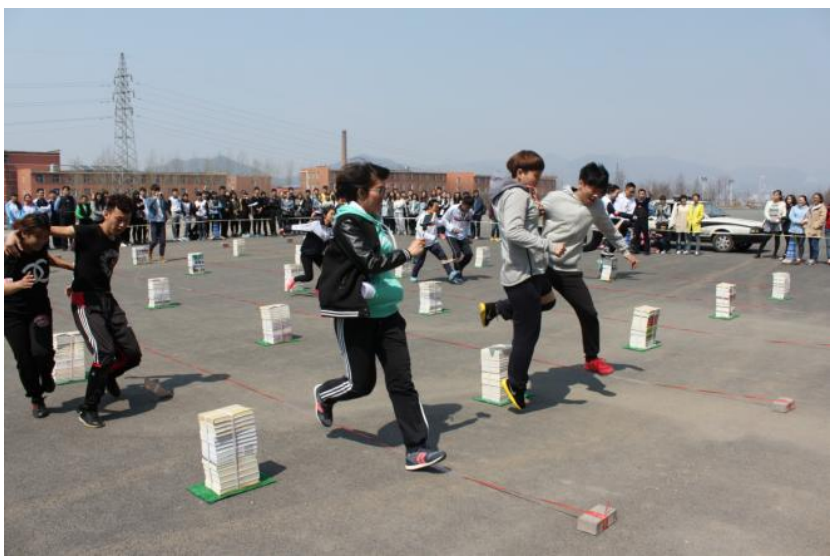

Fig. 1. Contestants were "crossing book mountain".

2) Books are the ladder of human progress: After finishing book matching and library stair game, the winning group can get 2 clue pieces.

Mode 1: One member draws the searching number envelope and aphorism card. The two members shall arrange the sequence of searching numbers or the characters of aphorism jointly according the rules. After arrangement, place them every other stair from up to down. Then go to the end stair, and there is a balloon envelope at the end platform. The group that first blows up the balloon wins. Books are not allowed to be placed on the ground. They should be placed according to the rules. If the arrangement sequence of books is wrong, the group fails.

Mode 2: carry books with head from the bottom stair to the top stair. The group that carries the largest amount of books within 60 seconds wins. If the book falls down in halfway, the one shall return back to the bottom stair to re-carry books. Once step on stairs, it is illegal to touch books with hands. If any one touch books with hands in halfway, he/she shall return back to the bottom stair to re-carry books.

Mode 3: member A takes one book and places it on the stair. Member B jumps up stairs with two feet. The number of characters in book name decides the jumping times of the member B. When the member B jumps to the corresponding stair, Member A can take one book and places on corresponding stair. Member B cannot touch book. The group that first get to the top stair wins. "Fig. 2" 


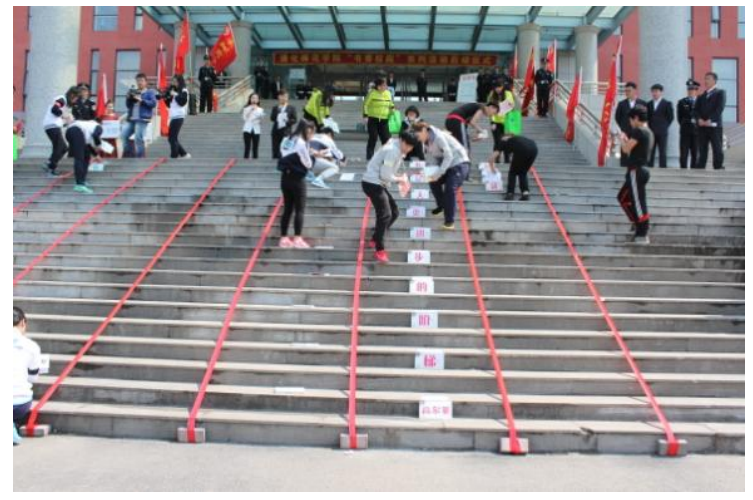

Fig. 2. Contestants were playing the game of "book, the ladder of human progress".

3) Book palace: Build the books on red carpet into a palace within one minute. And then build a road to the palace with books in Domino form. The public judges vote according to the effect of "book palace". The group that gets the largest number of votes gets two clue pieces. Push down the domino books, and the group with the largest number of falling-down books gets one clue piece.

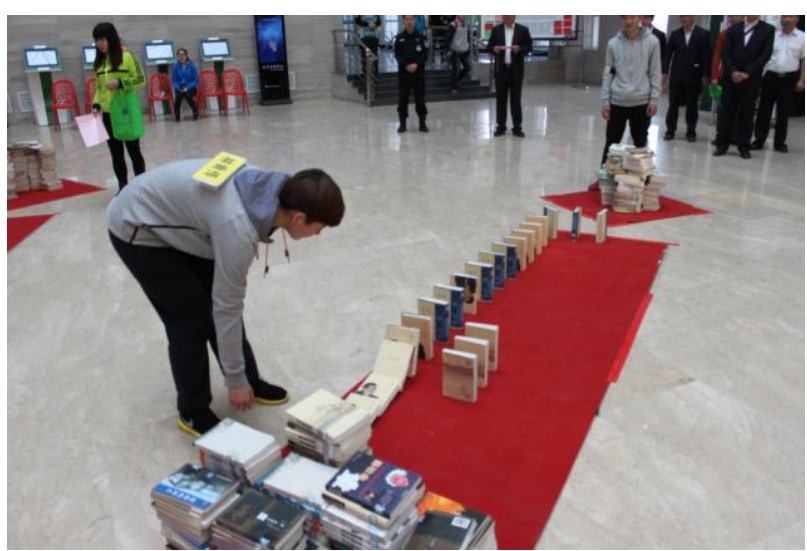

Fig. 3. Contestants were playing the game of "book palace".

4) Obtaining literature and seeking clues: Mode 1: draw materials and find the literature title. These materials include books, journal, newspapers, reference books, sample book, compact book, HowNet, superstar discovery, New Oriental, Wanfang and e-books. Complete the title and take photo and send it to WeChat. The group that first sends the photo to WeChat gets four clue pieces. The second group gets two clue pieces. The third group gets two clue pieces. The fourth group gets one clue piece. The last group gets no clue piece. Up to this link, the group with the largest number of clue pieces gets five basic votes.

Mode 2: complete title makeup game in the library hall. Complete the task and take photo and send the photo to WeChat. The group that first sends the photo to WeChat gets four clue pieces. The second group gets two clue pieces. The third group gets two clue pieces. The fourth group gets one clue piece. The last group gets no clue piece. Up to this link, the group with the largest number of clue pieces gets five basic votes.
Mode 3: each group has 20 books. These groups rank according to the numbers of book name they guess within 60 seconds. One member describes the book name, and the other guesses it. The describer cannot say the words of the book name. If fails, goes to next book. The group that guesses the largest number of book names gets four clue pieces. The second group gets two clue pieces. The third group gets two clue pieces. The fourth group gets one clue piece. The last group gets no clue piece. If the game is tied, carry out overtime. Up to this link, the group with the largest number of clue pieces gets five basic votes. "Fig. 4"

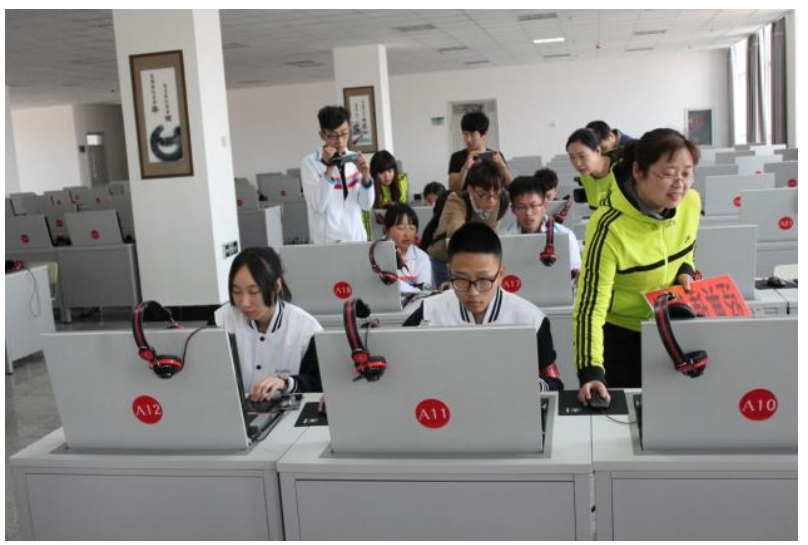

Fig. 4. Contestants were playing the game of "obtaining literature and seeking clues".

5) Look for library card and tear name tag: Put ten library cards in envelopes and hide them in the library hall. If both members find their library cards, they can borrow books from library. If find the library card of others, stick it on arm. Others are allowed to tear down the library card on arm. The name tag of the one whose library card has been found can be torn down. If the name tag and all library cards on arm are torn down by others, the member will be knocked out. Then the member shall give the clue pieces and library card to the one who make him/her out, and wait at judge's bench. They can also exchange clue pieces and library cards. The winner has the right to assign library cards and clue pieces. Match the clue pieces and give them to other groups. Make sure that each group can borrow books. The winner can get 10 basic votes. "Fig. 5"

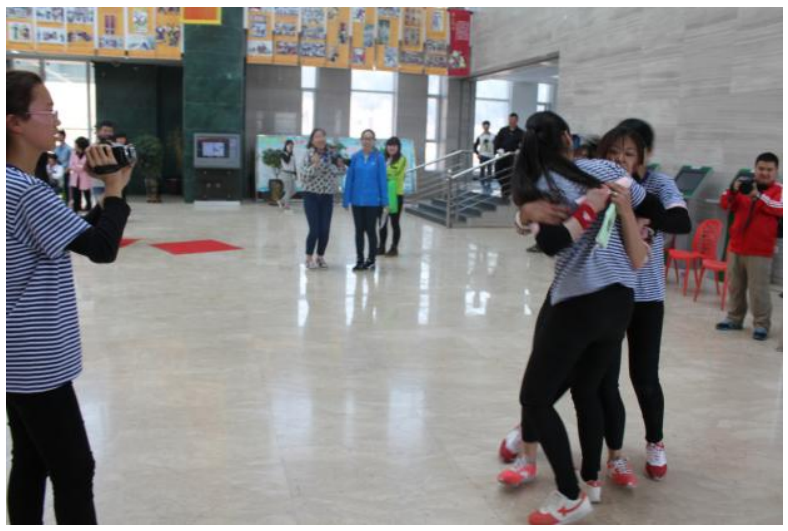

Fig. 5. Contestants were playing the game of "looking for library card, and tearing name tag". 
6) Book recommendation: Each group borrows the book according to the searching number on clue pieces. And then recommend the book to 50 pubic judges within 3 minutes. The public judges votes according to their recommendation performance. The group with the largest number of votes gets the final victory. "Fig. 6"

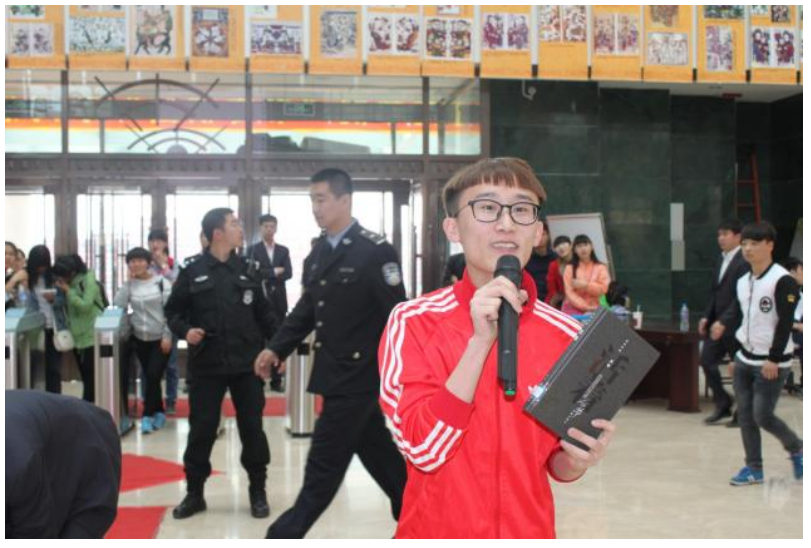

Fig. 6. Contestants were "recommending books".

\section{SUMMARY OF ACTIVITIES AND SPREAD OF EFFECT}

Due to early vigorous publicity, the departments of the university attached great importance to this activity. At that day flags of each faculty flew in front of library. The cheering squads were very vibrant. The scene of activity was very hot. With careful preparation of library staff, concerted cooperation, the activity was fully successful. After the finish of activity, the library processed the videos that faculties and the library shot and made into a short film, named "Running Reader". We broadcasted it through the campus broadcasting platform. The clicking times surpassed 2000. It is obvious that readers love this activity. Students readers reacted strongly and they couldn't image that the library could plan such a superior game. Library is not only a place for self-study. It is an energy paradise with fun, passion and connotation.

The activity has also been reported by 7 local media. It has enhanced the overall image of our university. Inspired by the activity of "Running Reader", readers' enthusiasm on all kinds of communication means, such as WeChat platform, library, message board and QQ group, are greatly improved. Under the atmosphere that the majority of readers care the library reading promotion work, the library also carried "network retrieval knowledge contest", "travel with a book" and other theme activities. And the effects were also very notable.

\section{The EXISTING Problems AND MAtTERS NEEDING ATTENTION IN THE IMPLEMENTATION}

The activity of "Running Reader" is an exploration for new reading promotion mode. The overall effect is very impressive. But there are still some problems. The author makes a summary and hopes to provide some references for future activities. The problems are as follows.

\section{A. The Activity Should Integrate Teaching in Entertainment and Pay More Attention to Education}

Many readers think this activity is just an entertainment after watching the video. Students participating in this activity only got entertainment. Therefore, library should guide readers to read books and boost the formation of reading atmosphere. It should start from reasonably constructing the reading knowledge system, integrate teaching in entertainment and blend more rational service and document literacy education.

\section{B. The Reading Promotion Work Should Also Take Teacher Groups into Account}

This activity took college students as main subject. We had to admit that we neglected the teacher groups fighting in the first line of scientific research. It is an import aspect to guide teachers to use library reasonably, effectively, smoothly and conveniently in the college reading promotion work.

\section{We Should Pay More Attention to the Final Sense of Readers}

The activity involved 15 faculties, but only a few dozen of students participated in the game. We should let more readers participate in the activity. For example, we can carry out the activity poster design contest and the reading promotion plan design contest, which enables more readers to participate in. In this way, they can really become the main subject of reading promotion. In addition, readers can approach reading. It is favorable for carrying out reading promotion work.

\section{THE IMPACT OF THE Mode ON READING PROMOTION WORK AND ITS SIGNIFICANCE}

"Running Reader" started from "the things readers loved". The overall positioning of the activity was on the combination of the popular and hot variety show mode among college students and the reading promotion work. It first integrated the recreational and sports activity into the reading promotion work, which made reading no longer dull and library no longer depressing. The promotion work became interesting. The librarians became vivacious and the readers felt no longer uninteresting. The reading promotion work can really walk into readers' heart and make reading more interesting. "Running Reader" looks like a firework with short splendor, but it has deeply affected the readers. It has extended the reading promotion work.

Firstly, the entry requirements clearly pointed out that the contestants should read the 100 books in the 2014 campus reading list. Thus, it pushed the campus reading to a climax. The required books soon become "scarce books". The number of students borrowing books increased, which increased the borrowing number of other books in library. At same time, the poster said to select 50 public judges to participate in the interaction link from the borrowing rank list, student assistants, readers' book recommendation group and WeChat. In order to get the qualification of public judge, the person-time entering library and WeChat care amount have been improved since the new term. 
Secondly, the activity of "Running Reader" has improved the utilization rate of library website, reader service QQ group and library WeChat. Other reading promotion activities with them as platforms also have drawn more attention than before. It has closed the distance between readers and library. The follow-up activities also got a good effect. Meanwhile, the utilization rate of previous desolate readers' book recommendation, network retrieval, message board, library echo wall and other service platforms has been obviously increased, which enables the corresponding service to be applied reasonably.

Thirdly, the activity of "Running Reader" realized the effective communication between readers and library. And library services have definite objects. It has enhanced the position of library in the minds of teachers and students and shaped a new service image among readers. Library changes its previous dull impression on students' minds, fully mobilize the enthusiasm of students in reading and attracts them to approach reading. Thus, library wonderfully walks into the views of students and teachers and quietly enters into the heart of every reader. Many readers said that this activity has changed their impression on library. Before library was just a place for self-study and only had old books. But now they feel that their library is fashionable, vital and substantial, and full of things they love. Readers know more about the voices of the reading promotion workers, and they start to understand and support their serious and diligent work.

Finally, such a joyful and passionate activity has made the reading promotion work lively and exciting. The cooperation ability of library and other departments has been greatly enhanced. In every step of the activity, we all got a good response, and every reading promotion worker was comforted. Their cohesive force grows stronger. Many librarians unexpectedly were moved to tears in watching the short film of "Running Reader". It was for students' attentive concentration, readers' smiling face because of loving library, cheering for the winner and diligent work of every one of us and overnight thinking on plan. Such a team with cohesion, creativity, willing to fight is bound to obtain a good achievement in future reading promotion work. May the towering Changbai Mountain be full of scholarly fragrance!

\section{REFERENCES}

[1] Wang Bo. Several Urgent Problems in Library Reading Promotion. Books and Information. 2011 (05).

[2] Wang Honghua. Library Reading Promotion Activities of Foreign Universities and Enlightenment. Library Journal. 2014 (08).

[3] Gong Meiling, Chu Cunkun, Zhang Hongtao, Du Baoxuan and Tan Liang. Study on the Three-dimensional Operation Mode of Reading Therapy. Journal of University Library. 2011 (05).

[4] Duan Mei, Fan Lijuan, Zhao Hui. Reading Promotion Innovation of Nanjing University of Science and Technology Library. Journal of University Library. 2011 (04).

[5] Zhu Xiaoling. Construction of Campus Cultural Brand Activities and Reading Promotion. Journal of University Library. 2011 (02). 